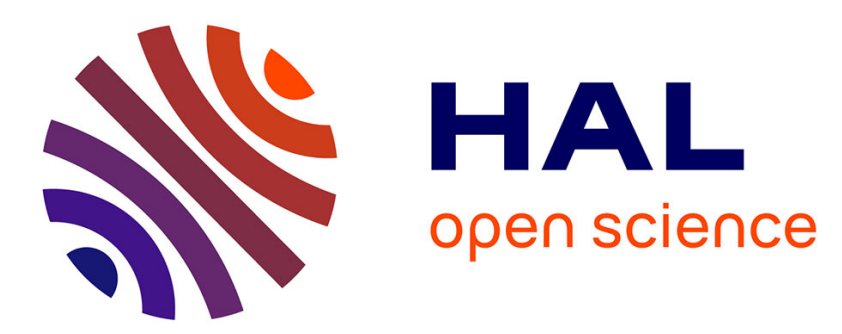

\title{
Adsorption of a chiral modifier on an oxide surface: Chemical nature of tartaric acid on rutile TiO2 (110)
}

E. Meriggio, R. Lazzari, S. Chenot, P. David, C. Methivier, X. Carrier, G. Cabailh, V. Humblot

\section{- To cite this version:}

E. Meriggio, R. Lazzari, S. Chenot, P. David, C. Methivier, et al.. Adsorption of a chiral modifier on an oxide surface: Chemical nature of tartaric acid on rutile TiO2 (110). Applied Surface Science, 2019, 493, pp.1134-1141. 10.1016/j.apsusc.2019.07.143 . hal-02340234

\section{HAL Id: hal-02340234 \\ https: / hal.sorbonne-universite.fr/hal-02340234}

Submitted on 30 Oct 2019

HAL is a multi-disciplinary open access archive for the deposit and dissemination of scientific research documents, whether they are published or not. The documents may come from teaching and research institutions in France or abroad, or from public or private research centers.
L'archive ouverte pluridisciplinaire HAL, est destinée au dépôt et à la diffusion de documents scientifiques de niveau recherche, publiés ou non, émanant des établissements d'enseignement et de recherche français ou étrangers, des laboratoires publics ou privés. 
Full length article

\title{
Adsorption of a chiral modifier on an oxide surface: Chemical nature of tartaric acid on rutile $\mathrm{TiO}_{2}(110)$
}

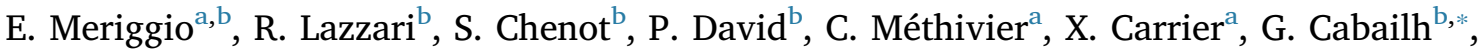 \\ V. Humblot ${ }^{\mathrm{a}, * *}$ \\ ${ }^{a}$ Sorbonne Université, UMR CNRS 7197, Laboratoire de Réactivité de Surface, 4 place Jussieu, 75252 Paris Cedex 05, France \\ ${ }^{\mathrm{b}}$ Sorbonne Université, UMR CNRS 7588, Institut des NanoSciences de Paris, 4 place Jussieu, 75252 Paris Cedex 05, France
}

\section{A B S T R A C T}

Tartaric acid (TA) is one of the most known chiral modifier used in heterogeneous enantioselective catalysis and understanding how it interacts with oxide supports is of significant importance for the design of efficient supported metal catalysts. This work presents a detailed surface science characterisation of $(R, R)$-TA adsorption on a rutile $\mathrm{TiO}_{2}(110)$ surface from a chemical and structural point of view. X-ray Photoelectron Spectroscopy (XPS), High Resolution Electron Energy Loss Spectroscopy (HREELS), Low Energy Electron Diffraction (LEED) and Scanning Tunnelling Microscopy (STM) were used to decipher the adsorption mode and geometrical arrangement of $\mathrm{TA}$ on $\mathrm{TiO}_{2}(110)$. For XPS analysis, spectra were compared to references recorded on model metal surfaces, namely Au(111) and Cu (110), on which a better understanding of the TA chemical nature is available. On $\mathrm{TiO}_{2}$, both XPS and HREELS converged to show the monotartrate chemical nature (only one acidic group is deprotonated) of the adsorbed TA molecules, while STM and LEED evidenced a $(2 \times 1) 2 \mathrm{D}$ network arrangement. TA molecules are anchored via both oxygen atoms of one carboxylate group binding directly to two adjacent $\mathrm{Ti}_{5 \mathrm{c}}$ of the underlying oxide surface. No chiral ordered domains were observed whatever the coverage, suggesting that surface chirality is induced at the molecular level.

\section{Introduction}

Heterogeneous enantioselective reactions, in which the synthesis of one enantiomer of a chiral compound is favoured with respect to the other, are essential for the production of fine chemicals, agrochemicals and pharmaceuticals [1]. One of the simplest and well-established approach for asymmetric hydrogenation reactions involves the adsorption of an organic chiral modifier onto a metal surface [2-5]. The efficiency of these systems relies on the combination of the catalytic activity of the metal and the asymmetric induction provided by the chiral modifier. At present, most fundamental studies have focused on model systems based on single crystal metal surfaces [6-9], while little is known on the role of the oxide support in supported metal catalysts and on the induction of chirality during the reaction. A detailed understanding of the interaction at a molecular level between the chiral modifier and the oxide support is thus an essential requirement for the comprehension of the entire catalytic system.

With the aim of exploring the fundamental interactions of chiral molecules with oxide surfaces, we have modelled a catalytic system with $(R, R)$-Tartaric Acid molecules (RR-TA the natural enantiomer) and rutile $\mathrm{TiO}_{2}(110)$ single crystals, selected as the prototypical chiral modifier and the oxide support, respectively. Tartaric acid (TA) is one of the most efficient chiral modifier [10], which presents at least three distinct chemical forms upon adsorption on metallic surfaces: bi-acid, monotartrate and bitartrate, in which none, one or both carboxylic acid groups are deprotonated, respectively. The adsorption of its $\mathrm{R}$ enantiomer has been intensively investigated on single crystal metal surfaces, such as $\mathrm{Cu}(110)$ [11-13] and on more efficient hydrogenation metal catalysts, like Ni(111) [14,15] and $\mathrm{Ni}(110)$ [16-18]. The other enantiomer, SS-TA, has also been studied in order to decipher how 2D chirality was conveyed to the metallic surfaces [7]. One major finding is that different molecular forms and orientations appear depending on coverage, time and adsorption temperature, giving rise to complex adsorption phase diagrams [7]. Moreover, different chiral expressions have been evidenced: on $\mathrm{Cu}(110)$ and $\mathrm{Ni}(111)$, lateral interactions between neighbouring molecules lead to the formation of highly ordered chiral arrays, which grow along non-symmetric directions of the underlying surface, annihilating all the mirror planes and leading to the formation of a 2D chiral network. Chirality is thus imparted on these surfaces not only locally due to the TA inherent chirality but also at a global 2D level. A different situation was reported for $\mathrm{Ni}(110)$, where no long-range organized structures are formed, but chirality is bestowed via a local chiral reconstruction of the underlying metal $\mathrm{Ni}$ atoms.

\footnotetext{
* Correspondence to: G. Cabailh, Sorbonne Université, UMR CNRS 7588, Institut des NanoSciences de Paris, 4 place Jussieu, 75252 Paris Cedex 05, France.

** Correspondence to: V. Humblot, Sorbonne Université, UMR CNRS 7197, Laboratoire de Réactivité de Surface, 4 place Jussieu, 75252 Paris Cedex 05, France. E-mail addresses: gregory.cabailh@sorbonne-universite.fr (G. Cabailh), vincent.humblot@sorbonne-universite.fr (V. Humblot).
} 

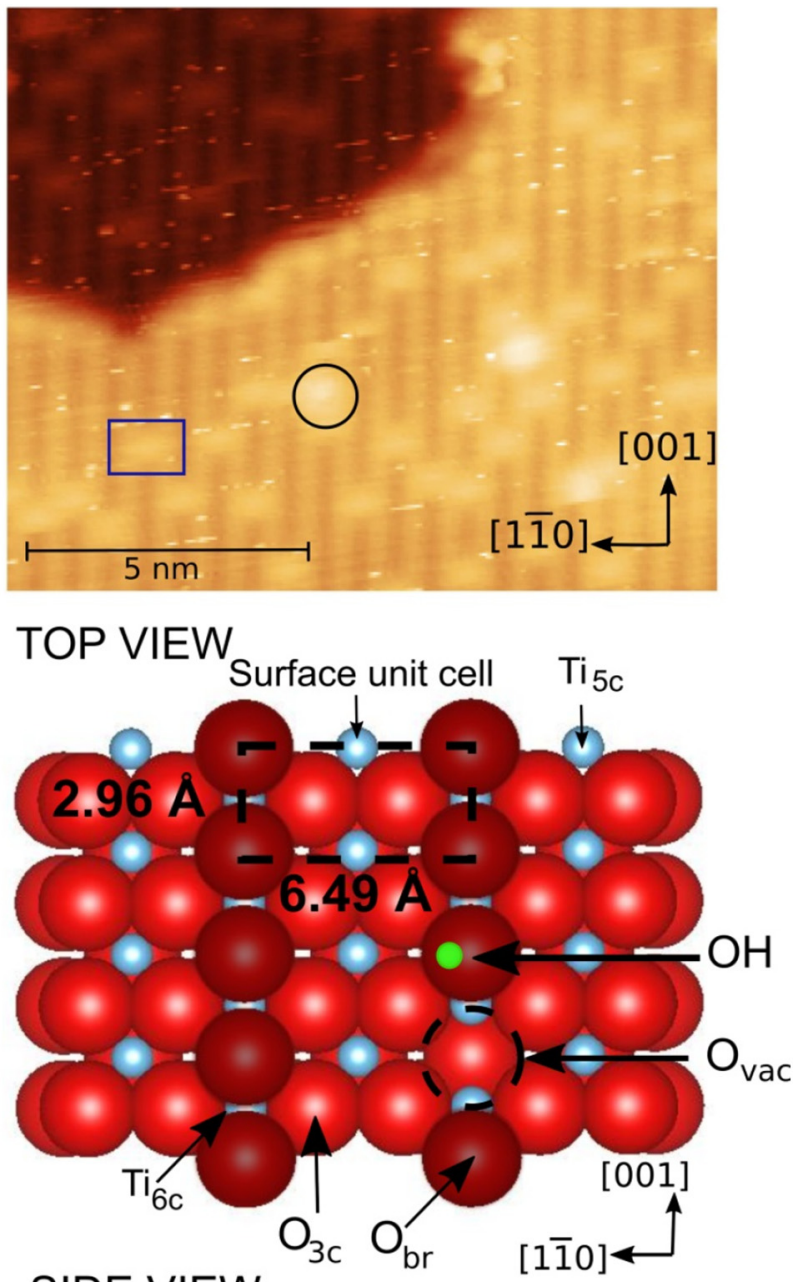

SIDE VIEW

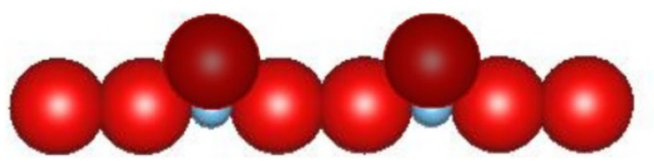

Fig. 1. Top: STM image of the clean rutile $\mathrm{TiO}_{2}(110)$ surface $(0.9 \mathrm{~V}, 100 \mathrm{pA})$. Examples of $\mathrm{O}_{\mathrm{vac}}$ and $\mathrm{OH}$ group are marked with a blue rectangle and a black circle, respectively. Bottom: Ball model of the rutile $\mathrm{TiO}_{2}(110)$ surface. Ti atoms, in plane $\mathrm{O}$, bridging $\mathrm{O}$ and hydrogen atoms are depicted in blue, red, dark red and green, respectively. The black rectangle shows the $(1 \times 1)$ surface unit cell.

The ever-increasing interest for its proven or/and promising applications in a wide range of fields and the versatility of its characterisation by surface science techniques has made rutile $\mathrm{TiO}_{2}$ one of the most investigated oxide material $[19,20]$. Most studies have been devoted to the (110) surface, the thermodynamically most stable one, which is schematically represented in Fig. 1: $\mathrm{O}$ and Ti atoms with two different coordinations compose the surface. Along the [001] direction, rows of five-fold coordinated $\mathrm{Ti}$ atoms $\left(\mathrm{Ti}_{5 \mathrm{c}}\right.$ ) alternate with rows of three-fold $\mathrm{O}$ atoms $\left(\mathrm{O}_{3 \mathrm{c}}\right)$ and six-fold $\mathrm{Ti}$ atoms $\left(\mathrm{Ti}_{6 \mathrm{c}}\right)$. Two-fold $\mathrm{O}$ atoms, also called bridging- $\mathrm{O}\left(\mathrm{O}_{\mathrm{br}}\right)$, are bonded on top of the $\mathrm{Ti}_{6 \mathrm{c}}$ atoms, protruding above the surface layer. The $(1 \times 1)$ surface unit cell is rectangular, with unit cell parameters of $6.49 \AA$ and $2.96 \AA$ along the [110] and [001] directions, respectively (Fig. 1). The two most common defects, oxygen vacancies $\left(\mathrm{O}_{\mathrm{vac}}\right)$ and hydroxyl $(\mathrm{OH})$ groups, are also represented in the figure. As shown in Fig. 1 (top), the clean $\mathrm{TiO}_{2}(110)$ surface is imaged in STM as alternate parallel brighter and darker rows running along the [001] direction, which correspond to surface $\mathrm{Ti}_{5 \mathrm{c}}$ and bridging $\mathrm{O}$ atoms, respectively, in contrast to the surface topography $[19,20]$. $\mathrm{O}_{\text {vac }}$ and $\mathrm{OH}$ groups are imaged in STM as bright spots on the dark $\mathrm{O}_{\mathrm{br}}$ rows, as evidence in Fig. 1 (top). The two types of defects are distinguished mainly by their contrast with respect to the lateral $\mathrm{Ti}_{5 \mathrm{c}}$ rows: while $\mathrm{O}_{\mathrm{vac}}$ have the same contrast as $\mathrm{Ti}_{5 \mathrm{c}}$ rows, $\mathrm{OH}$ groups appear instead brighter.

To date, the reactivity of rutile $\mathrm{TiO}_{2}(110)$ with other non-chiral carboxyl-containing molecules has been the focus of some attention, driven by the existing and potential applications for solar cells, selfassembled monolayers, gas sensors and heterogeneous catalysis just to name a few [20]. Studies have ranged from simple carboxylic acids, such as formic [21-29] and acetic [28,30-32] acids, to larger and more complex ones, containing multiple functional moieties and particularly interesting in the development of functionalised surfaces [33-40]. All these molecules have displayed a general common tendency to deprotonate one or more $\mathrm{COOH}$ groups, with the carboxylate $\mathrm{O}$ atoms binding to an adjacent pair of $\mathrm{Ti}_{5 \mathrm{c}}$ atoms along the [001] direction and the parted $\mathrm{H}$ atoms possibly forming surface hydroxyls [20]. To our knowledge only the adsorption of the chiral L-cysteine, a complex amino acid, has been investigated in an experimental study on the rutile $\mathrm{TiO}_{2}(110)$ surface [41]. However, no references are available on the adsorption of simple chiral carboxyl-containing molecules, showing the novelty of the work about chirality induced at oxide $\mathrm{TiO}_{2}$ surfaces towards enantiospecific heterogeneous catalysis.

In this work, we used a combination of X-Ray Photoelectron Spectroscopy (XPS), High-Resolution Electron Energy Loss Spectroscopy (HREELS), Scanning Tunnelling Microscopy (STM) and Low Energy Electron Diffraction (LEED) to investigate the interaction between the rutile surface and RR-TA molecules, deposited by sublimation at room temperature under Ultra-High Vacuum (UHV) conditions. XPS spectra recorded on model metal surfaces, namely Au(111) and $\mathrm{Cu}(110)$, were used as references and compared to those acquired on rutile single crystals. Combined with HREELS, a powerful surface science technique well suited for vibrational studies, these tools allowed to elucidate the molecular adsorption chemistry. Moreover, STM and LEED provided information on the 2D layer structure and anchoring points of the molecules.

\section{Experimental}

Experiments have been carried out in four different ultrahigh vacuum (UHV) systems, with base pressures of $10^{-10}$ mbar or better. All chambers contain facilities for sample preparation and subsequent characterisation techniques. More precisely, one chamber is equipped with a HREELS spectrometer for vibrational analysis; a second one houses facilities for XPS, LEED and Polarisation-Modulation Reflection Absorption Infra-Red Spectroscopy (PM-RAIRS) experiments, while two other UHV systems comprise LEED and STM one of which is also combined with XPS. Although the four UHV chambers have different geometries, heating devices and sputter guns with specific operating parameters, the cleaning and deposition conditions are adapted and calibrated for each individual chamber to obtain the same TA adlayer regardless of the UHV chamber used.

Rutile $\mathrm{TiO}_{2}(110)$ single crystals were supplied by Mateck $\mathrm{GmbH}$, Germany, while $\mathrm{Cu}(110)$ and $\mathrm{Au}(111)$ were provided by Surface Preparation Laboratory, The Netherlands, with a purity of $99.99 \%$ (4 N) and alignment accuracy of $0.1^{\circ}$. The samples were mounted on metallic (Ta or Mo) plates. In each chamber, the samples were prepared using a standard UHV cleaning procedure, involving multiple cycles of $\mathrm{Ar}^{+}$ sputtering (energy $1 \mathrm{keV}$ ) followed by annealing at different temperatures ( $1000 \mathrm{~K}$ for rutile, $850 \mathrm{~K}$ for copper and gold). Surface crystallinity was checked by LEED, while the sample cleanliness was confirmed by either the absence of contaminations by XPS or the absence of $\mathrm{CH}$ vibrations by HREELS. The standard UHV cleaning preparation of $\mathrm{TiO}_{2}(110)$ single crystals is known to lead to an amount of $\mathrm{O}$ vacancies $\left(\mathrm{O}_{\text {vac }}\right)$ between 5 and 10\%, which therefore does not majorly affect TA dosing conditions. However, in the time required to slowly cool down, transfer the sample and approach the evaporator for dosing molecules, 
most $\mathrm{O}_{\mathrm{vac}}$ are filled by hydroxyl groups from the dissociation of residual water in the UHV chamber [20].

$(R, R)$-Tartaric acid powder, supplied by Acros Organics (Fisher Scientific SASFrance), was deposited by thermal evaporation from a glass crucible resistively heated by flowing current in a metallic wire wrapped around it. The evaporator, thoroughly degassed for several hours, was pumped by a turbomolecular pump, isolated from the main UHV chamber by a gate valve. After opening the gate valve, the evaporator was inserted in the chamber, in front of the crystal surface held at room temperature; the base pressure during the TA dosing was around $10^{-9}$ mbar. TA calibration is performed either by XPS or STM. The molecular coverage is defined a posteriori as the half of the exposed $\mathrm{Ti}_{5 \mathrm{c}}$ atoms, i.e. $2.6 \times 10^{14} \mathrm{~cm}^{-2}$, knowing how the molecule binds to the surface. The as-prepared surfaces are then characterised by XPS for all interfaces and additionally by in-situ PM-RAIRS on $\mathrm{Cu}(110)$ and $\mathrm{Au}$ (111), and STM, LEED and HREELS on $\mathrm{TiO}_{2}$.

XPS electron spectroscopy was performed using a monochromatized aluminum Ka X-ray source (photon energy $\mathrm{h} \nu=1486.6 \mathrm{eV}$ ) and a hemispherical analyser (Phoibos 100 1D Delay Line Detector) from SPECS. All spectra were recorded at normal emission in constant analyser energy (CAE) mode with pass energies of $100 \mathrm{eV}$ (survey spectra) and $20 \mathrm{eV}$ (high-resolution spectra). The spectra were fitted using the Casa XPS Software and a Gaussian/Lorentzian ratio equal to 70/30 (fitting parameters can be found in the supporting information).

STM images were obtained at room temperature in the constant current mode using electrochemically etched tungsten tips which are polarised, while the sample is held at ground potential. For $\mathrm{TiO}_{2}$ the bias was always positive, meaning that empty states, mainly of $\mathrm{Ti}$ character, were probed [19]. All images were analysed using the Gwyddion 2.51 software. The main analysis involved plane and threepoint levelling, image cropping to optimise the contrast between different terraces and line profile extraction to estimate the mean distance between neighbouring molecules. LEED images were acquired using a Specs Er-LEED 1000-A setup and a filament current of 2.2 A.

Infrared PM-RAIRS spectra were acquired using a Nicolet 5700 spectrometer in conjunction with a mercury cadmium telluride wideband detector cooled by liquid nitrogen. A ZnSe window was used as an IR window between the spectrometer and the UHV chamber. The s- and p- beam polarisations were generated with a ZnSe polariser and ZnSe photoelastic modulator placed before the sample. In all experiments reflection optics were optimised for an incident angle of $85^{\circ}$. Spectra were averaged over 1024 scans and recorded with a resolution of $8 \mathrm{~cm}^{-1}$.

HREELS analysis was carried out with an electrostatic spectrometer LK2000 from LK-Tech, possessing a dual stage cylindrical monochromator at $127^{\circ}$ and a rotatable analyser. All experiments were performed in specular geometry, with an incident angle of $60^{\circ}$ with respect to the surface normal, at several beam energies ( 8.8 and $12.8 \mathrm{eV}$ ). The typical resolution achieved for the clean $\mathrm{TiO}_{2}$ surface was around $9 \mathrm{meV}$ and $5 \times 10^{5}$ counts/s as estimated from the full-width-at-halfmaximum (FWHM) and counting rate of the elastic peak, respectively.

\section{Results and discussion}

RR-TA gas-phase deposition on $\mathrm{TiO}_{2}$ has been studied by XPS for different dosing times, to be able to follow all stages of growth, from single molecules to a complete monolayer. Assuming a homogeneous molecular film, the layer thickness, $t$, was estimated from the XPS intensity ratio $I_{s} / I_{a}$ using the Ti2p (the substrate is denoted "s") and C1s (referenced as the adsorbate, denoted "a") core levels and Eq. (1):

$\frac{I_{s}}{I_{a}}=\frac{n_{s}}{n_{a}} \frac{T_{s}}{T_{a}} \frac{\sigma_{s}}{\sigma_{a}} \frac{\lambda_{s s}}{\lambda_{a a}} \frac{e^{-t / \lambda_{s a}}}{1-e^{-t / \lambda_{a a}}}$

where the take-off angle of the emitted photoelectrons, is implicitly assumed equal to $90^{\circ}$, the analysis being in a normal emission configuration. Moreover, $\mathrm{n}_{\mathrm{s}}$ and $\mathrm{n}_{\mathrm{a}}$ are the atomic concentrations of the elements; $\lambda_{\mathrm{ss}}, \lambda_{\mathrm{aa}}$ and $\lambda_{\mathrm{sa}}$ are the inelastic mean free paths of a substrate photoelectron in the substrate, of an adsorbate photoelectron in the adsorbate layer and of a substrate photoelectron in the adsorbate layer, respectively. They were estimated using the program QUASES-IMFPTPP2M [42]. $\mathrm{T}_{\mathrm{s}}$ and $\mathrm{T}_{\mathrm{a}}$ are the transmission functions at the corresponding photoelectron kinetic energies, while $\sigma_{s}$ and $\sigma_{a}$ are the Scofield photoemission cross sections. A saturated monolayer coverage is obtained after approximately $30 \mathrm{~min}$ of dose, with an equivalent thickness of about $5 \AA$.

To decipher the TA molecular chemical state on $\mathrm{TiO}_{2}$, several tests were made by means of PM-RAIRS and conventional RAIRS. However, unlike what was reported in literature $[40,43,44]$, no workable signal could be detected during TA deposition. Compared to metal surfaces, performing IR spectroscopy on oxide surfaces is much more challenging. This is mainly due to their inherent optical properties, which result in signal to noise $(\mathrm{S} / \mathrm{N})$ ratios one to two order of magnitude lower with respect to metal substrates. Nevertheless, impressive progress has been recently achieved and IR spectra on metal oxide surfaces have been successfully recorded by means of dedicated UHV IR spectroscopy set-ups $[43,44]$. This has allowed to probe the interactions of a number of adsorbates, including $\mathrm{CO}, \mathrm{CO}_{2}, \mathrm{H}_{2} \mathrm{O}$ and some carboxylic acids, with both oxide single crystals and powders, such as $\mathrm{ZnO}, \mathrm{TiO}_{2}$ and $\mathrm{CeO}_{2}$ $[43,44]$. In the successful experiments reported in literature, the spectrometer was placed under vacuum, which results in $(\mathrm{S} / \mathrm{N})$ in absorbance of the order of $10^{-6}$. In our work, $(\mathrm{S} / \mathrm{N})$ is approximately one order of magnitude lower, explaining the weaker sensitivity during the acquisition. As an alternative approach, the chemical nature of TA was investigated by means of XPS by focusing on the C1s region since on $\mathrm{TiO}_{2}$ the O1s molecular signal overlaps with the bulk oxide atoms and surface hydroxyl contributions.

In order to strengthen the analysis of the different XPS contributions of adsorbed TA on rutile, reference spectra were first obtained on two model metal surfaces, on which the chemical adsorption form of TA is well known [11-13]. More precisely, $\mathrm{Au}(111)$ and $\mathrm{Cu}(110)$ surfaces have been selected, on which neutral bi-acid molecules and monotartrate species are expected at room temperature, respectively.

In this respect, in-situ PM-RAIRS (see Supporting Information) and XPS were employed to confirm the TA chemical state on the model metal surfaces selected.

Following the PM-RAIRS confirmation (Supporting Information: neutral bi-acid TA molecules on $\mathrm{Au}(111)$ and monotartrate TA species on $\mathrm{Cu}(110)$ ), reference XPS spectra of $\mathrm{C} 1 \mathrm{~s}$ and $\mathrm{O} 1 \mathrm{~s}$ core levels were obtained after TA deposition on $\mathrm{Au}(111)(2.5 \AA \sim 0.4 \mathrm{ML})$ and $\mathrm{Cu}(110)$ (3.5 $\sim 0.7 \mathrm{ML})$ surfaces and Fig. 2 reports the corresponding background-removed XPS spectra. For the gold surface, two distinct peaks are identified in the $01 \mathrm{~s}$ region, a dominant contribution at $532.5 \mathrm{eV}$, attributed to the superposition of peaks arising from the $\mathrm{OH}$ alcohol groups and the $\mathrm{C}=\mathrm{O}$ oxygen atoms from the carboxylic group and a smaller feature at $533.5 \mathrm{eV}$ ascribed to the $\mathrm{OH}$ acid groups. The peak attribution is in line with the work of Rieger et al. for RR-TA on Cu(111) [45]. Rieger et al. reported binding energies of $532.3 \mathrm{eV}$ and $532.7 \mathrm{eV}$ for $\mathrm{C}-\mathrm{OH}$ and the $\mathrm{C}=\mathrm{O}$, respectively. In view of the small $\mathrm{BE}$ difference between these two contributions, a unique peak at $532.5 \mathrm{eV}$ was considered in our analysis. The area ratio of the two $\mathrm{O}$ contributions is $\sim 2: 1$, as one would expect from the stoichiometry of the molecule. Consistently, the $\mathrm{C} 1 \mathrm{~s}$ peak displays two molecular contributions at binding energies of $286.7 \mathrm{eV}$ and $289.3 \mathrm{eV}$, assigned to the central C-OH atoms and the carboxylic $\mathrm{C}$ atoms, respectively. For them, the peak area ratio is $\sim 1: 1$, in line with the expected stoichiometry.

For the $\mathrm{Cu}(110)$ surface, the $\mathrm{O} 1 \mathrm{~s}$ spectrum presents an extra peak at $531.5 \mathrm{eV}$ compared to the gold surface, assigned to the $\mathrm{O}$ atoms in the carboxylate group. Consistently, in the $\mathrm{C} 1 \mathrm{~s}$ region one additional contribution is observed at $288.1 \mathrm{eV}$, associated to the carboxylate $\mathrm{C}$ atoms. The $\mathrm{COO}^{-} / \mathrm{COOH}$ and $\mathrm{COO}^{-} / \underline{\mathrm{COOH}}$ area ratios are about 3:1 and $1.5: 1$, respectively, whereas one would expect $2: 1$ and $1: 1$ for 

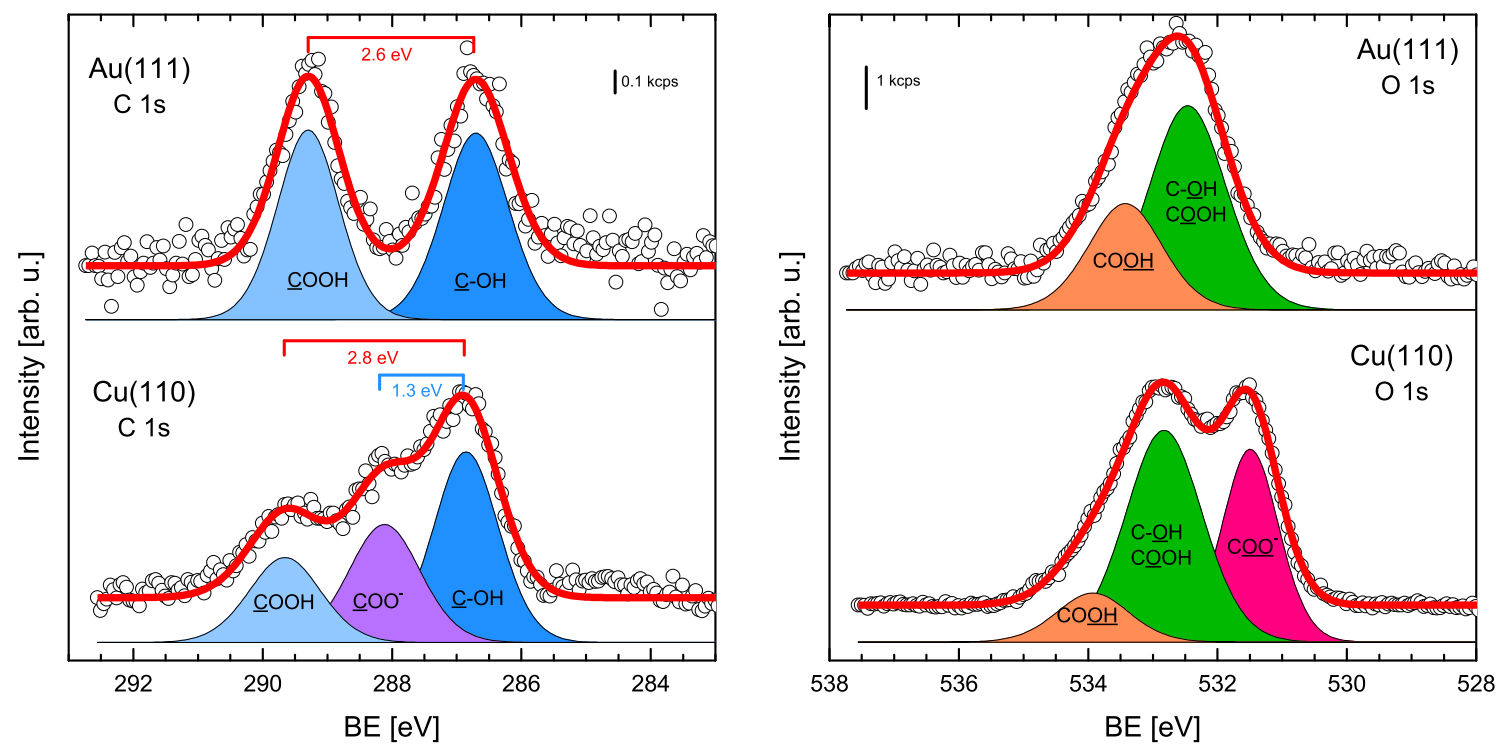

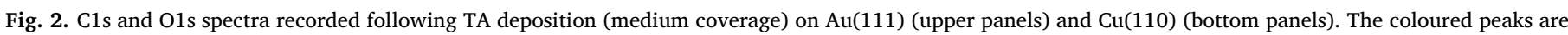
the fit components. The red line and black dots represent the sum of the fitted components and the raw data, respectively.

monotartrate species. This would suggest that some molecules are completely deprotonated. However, the stoichiometric ratios are globally in line with the expected combined values $\left(\left[\mathrm{COO}^{-}+\mathrm{COOH}\right]:[\mathrm{C}-\right.$ $\mathrm{OH}+\mathrm{C}-\mathrm{OH}]=1: 1)$. The energy splitting values are in very good agreement with the work of Rieger et al. for RR-TA on $\mathrm{Cu}(111)$ [45]. A degree of deprotonation higher than expected was already reported for RR-TA and SS-TA on Cu(531) [46] and for meso RS-tartaric acid, RRtartaric acid, and the racemic mixture of RR-TA and SS-TA on $\mathrm{Cu}(111)$, but no explanation was proposed [45]. Syres et al. also observed a discrepancy from the expected stoichiometry for the adsorption of malic acid (HOOC- $\mathrm{CH}_{2}-\mathrm{HCOH}-\mathrm{COOH}$ ) on $\mathrm{Cu}(110)$ [39].

In the following discussion, the energy splitting indicated in red and blue in Fig. 2 between C1s contributions will be used as fingerprints for the neutral carboxyl groups $(2.8-2.6 \mathrm{eV})$ and the deprotonated carboxylates $(1.3 \mathrm{eV})$.

Using the chemical information obtained from the model metal surfaces, we then tried to decipher the chemical form of TA molecules adsorbed on rutile. Fig. 3 displays the evolution of the C1s spectra recorded at increasing exposures of RR-TA on $\mathrm{TiO}_{2}(110)$. At all coverages two peaks with almost equal intensity are identified. One at $287.1 \mathrm{eV}$, assigned to central C-OH carbon atoms, and one at $289.3 \mathrm{eV}$. A detailed analysis of the energy splitting between the main $\mathrm{C} 1 \mathrm{~s}$ components was carried out. For TA adsorption on $\mathrm{Au}(111)$ and $\mathrm{Cu}(110)$ the carboxylic groups are located $2.6 \mathrm{eV}$ and $2.8 \mathrm{eV}$ away from the central $\mathrm{C}-\mathrm{OH}$ carbon atoms, respectively (Fig. 2). Moreover, on $\mathrm{Cu}(110)$ the energy splitting found between the carboxylate functionality and the central C$\mathrm{OH}$ carbon atoms is $1.3 \mathrm{eV}$. On $\mathrm{TiO}_{2}$ the energy separation between the two contributions remains constant at about $2.2 \mathrm{eV}$ for the different TA layer thicknesses, suggesting that TA molecules do not undergo important chemical modifications with increasing doses. This energy splitting value of the C1s peaks is located in between those attributed on the model metal surfaces to the carboxylate functionalities $(1.3 \mathrm{eV})$ and those attributed to the carboxylic acid groups (2.6-2.8 eV). Energy splitting values between the central carbon atom and the $\mathrm{COO}^{-}$peak were found to range between 1.0 and $1.3 \mathrm{eV}$ for chiral malic acid on $\mathrm{Cu}$ (110) depending on the surface coverage [47]. In addition to this, splitting values between 1.4 and $1.6 \mathrm{eV}$ are also found in literature for chiral and racemic monotartrate and bitartrate TA molecules on $\mathrm{Cu}$ (110) and $\mathrm{Cu}(111)[45,48]$. Conversely, as for the $\mathrm{C}-\mathrm{OH} / \mathrm{COOH}$ splitting, values of 2.4 and $3.1 \mathrm{eV}$ were found for chiral and/or racemic TA on $\mathrm{Cu}(110)$ and $\mathrm{Cu}(111)$, respectively [45,48]. Hence the intermediate energy splitting of $2.2 \mathrm{eV}$ on $\mathrm{TiO}_{2}$ could be explained by the

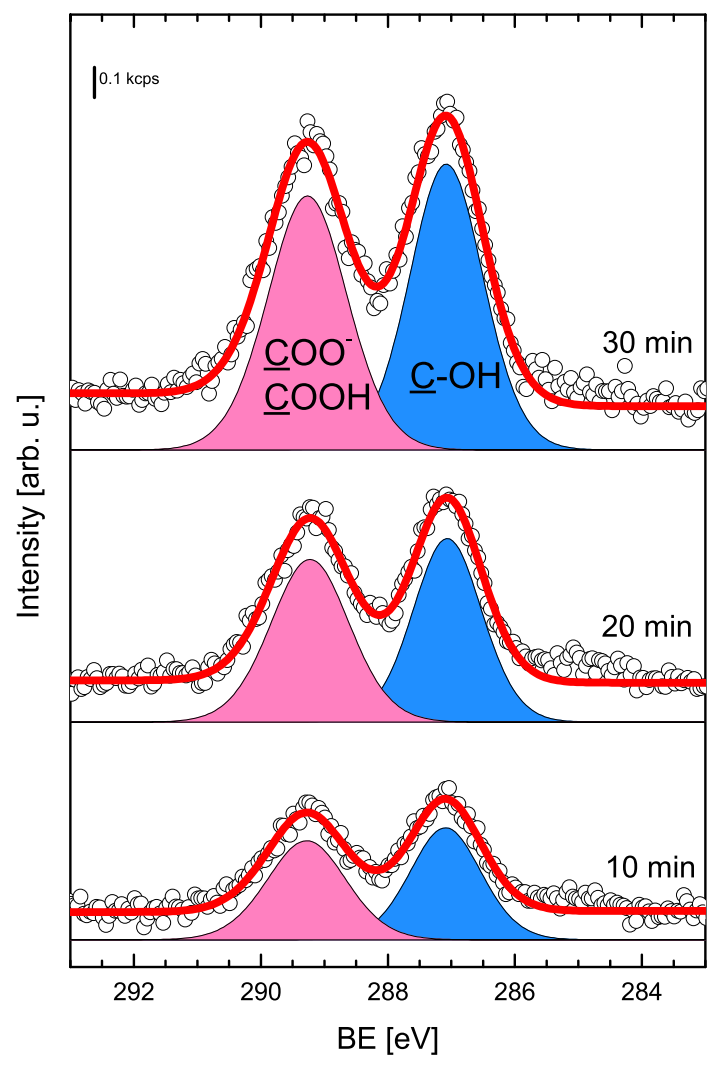

Fig. 3. Evolution of $\mathrm{C} 1 \mathrm{~s}$ peaks for increasing doses of $\mathrm{TA}$ on the rutile $\mathrm{TiO}_{2}(110)$ surface. To allow a direct comparison, the spectra have been normalised to the Ti2p3/2 peak maximum. The peak fitting attribution is explained in the text.

simultaneous presence of $\mathrm{COO}^{-}$and $\mathrm{COOH}$ groups on the oxide surface, which would possibly suggest that monotartrate species are adsorbed on $\mathrm{TiO}_{2}$. In this case, it would mean that, unlike the metallic case, the $\mathrm{COO}^{-}$and $\mathrm{COOH}$ groups are not resolved on $\mathrm{TiO}_{2}$, as previously reported in the work of Zhang [38], resulting therefore in a broader contribution at $289.3 \mathrm{eV}$ in our work. The presence of a unique peak could possibly be explained by a different charge transfer between TA and metal surfaces compared to $\mathrm{TA}$ and $\mathrm{TiO}_{2}$, leading to a different 


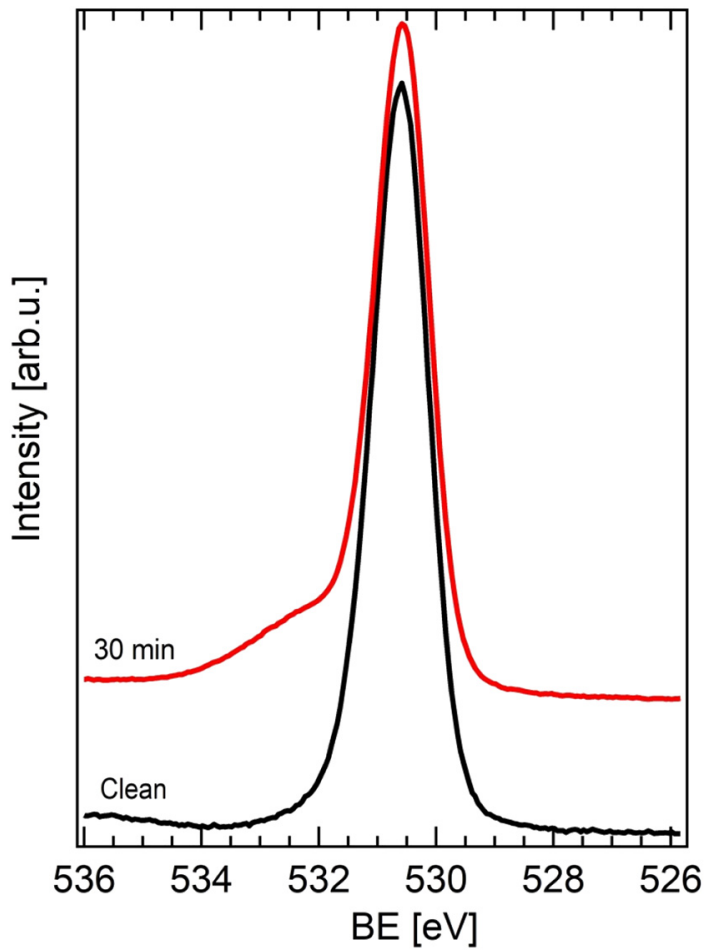

Fig. 4. O 1s spectra recorded for the clean $\mathrm{TiO}_{2}(110)$ surface (in black) and the TA-dosed (30 min dosing) $\mathrm{TiO}_{2}(110)$ surface (in red).

peak displacement on $\mathrm{TiO}_{2}$ compared to $\mathrm{Au}$ and $\mathrm{Cu}$. The hypothesis of partial deprotonation may also be suggested also by the fit of the $\mathrm{C} 1 \mathrm{~s}$ peaks (Fig. 3) and more precisely by the broadened width of the peak at $289.3 \mathrm{eV}$, with respect to the one at $287.1 \mathrm{eV}$ (fwhm $=1.5 \mathrm{eV} v s 1.35 \mathrm{eV}$ for $30 \mathrm{~min}$ of dose, i.e. saturation coverage), suggesting that two types of $\mathrm{C}$ atoms would contribute to the high $\mathrm{BE}$ peak, the carboxylic and carboxylate $\mathrm{C}$ atoms. However, the broadening observed, despite being comparable to that found in literature for terephthalic acid (TPA) molecules on the same rutile (110) surface [38], remains moderate and prevents an unambiguous assignment of TA chemical nature only by means of XPS. For this reason, additional HREELS experiments were carried out to further elucidate TA adsorption on $\mathrm{TiO}_{2}$.

Fig. 4 shows the O1s spectra recorded i) for the clean $\mathrm{TiO}_{2}$ surface and ii) after a saturation dose of RR-TA (30 min). Upon TA adsorption, a shoulder develops on the high BE energy side of the peak. Performing the same analysis as for the C1s spectra is more complicated since two intrinsic contributions originating from the lattice $\mathrm{O}$ atoms and from surface hydroxyl species are already present on the clean surface and partially cover the molecular peaks. A plausible fit for the O1s region supporting the C1s assignment is proposed (see Supporting Information), but it could not have been done without the above complementary information provided by the $\mathrm{C} 1 \mathrm{~s}$ analysis. Since, the intensity of TA contributions is far weaker than the intrinsic $\mathrm{TiO}_{2}$ components, the fit was possible and realistic only by fixing all the fit parameters. Nevertheless, by applying these specific fits, one can decipher the presence of both $\mathrm{C}=\mathrm{O}$ and $\mathrm{COO}^{-}$together on the $\mathrm{O} 1 \mathrm{~s}$ region, therefore supporting the first hypothesis deduced from the $\mathrm{C} 1 \mathrm{~s}$ analysis.

HREELS measurements were carried out to confirm the chemical nature of adsorbed species as well as the adsorption mechanism tentatively suggested by XPS experiments. Generally speaking, HREEL spectra of oxide surfaces are dominated by strong surface optical phonons followed by their multiple losses and combination excitations at higher energy losses $[49,50]$. For the $\mathrm{TiO}_{2}(110)$ surface, three optical phonons appear at 365,445 and $755 \mathrm{~cm}^{-1}$. These intense intrinsic features hamper the observation of molecular contributions, which are usually of much lower oscillator strengths. Different methods have thus

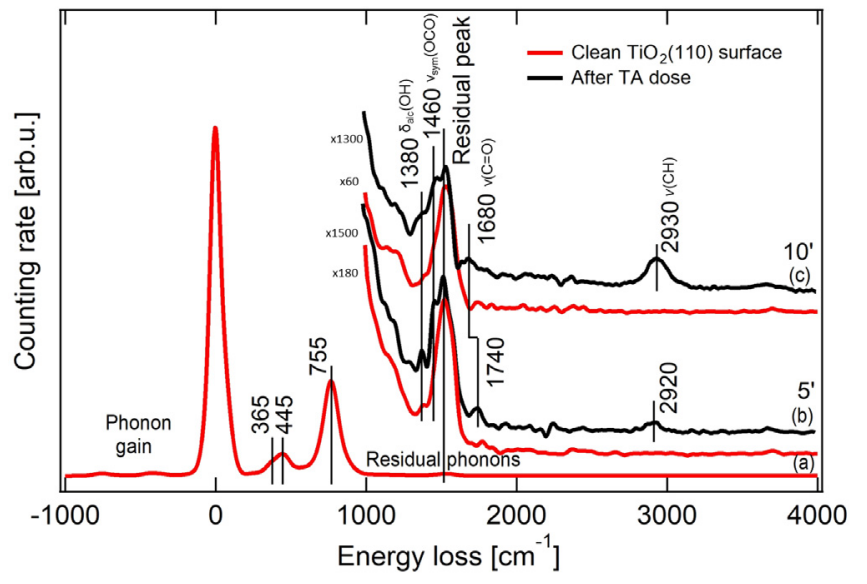

Fig. 5. (a) Fourier deconvoluted HREEL spectrum for the clean $\mathrm{TiO}_{2}(110)$ surface recorded at an impact energy of $8.8 \mathrm{eV}$. (b) Fourier deconvoluted HREEL spectra for the clean $\mathrm{TiO}_{2}(110)$ surface (red) and after a TA dose of 5 min (black) at $12.8 \mathrm{eV}$. (c) Zoom of Fourier deconvoluted HREEL spectra for the clean $\mathrm{TiO}_{2}(110)$ surface (red) and after a TA dose of 10 min (black) at a beam energy of $8.8 \mathrm{eV}$.

been developed to completely or at least partially eliminate the multiple phonon contribution. In this work, a procedure proposed by Cox and co-workers based on a Fourier log deconvolution technique has been applied [51]. The effectiveness of the method is shown in Fig. 5(a) for the clean $\mathrm{TiO}_{2}(110)$ surface, where most of the multiple loss features have been suppressed, with the exception of a residual peak at about $1500 \mathrm{~cm}^{-1}$ which partially hinders the less intense molecular contributions in this region [22].

Fig. 5 also shows the Fourier deconvoluted spectra recorded for the clean surface (in red) and after a TA dose (in black) of $5 \mathrm{~min}$ (b) and $10 \mathrm{~min}$ (c), respectively. Based on previous calibrations, $10 \mathrm{~min}$ of dose corresponds to one saturated monolayer. It has to be mentioned that the counting rate was high on the clean surface but it reduced drastically after TA dose as already evidenced in previous works [22]. Spectra presented in Fig. 5 have been normalised to the residual peak at $1500 \mathrm{~cm}^{-1}$, but only to visually allow a direct comparison in the energy region of interest where molecular peaks are expected. Some molecular contributions are clearly detected. Losses observed at 1380 and $1460 \mathrm{~cm}^{-1}$ are assigned to the deformation of the alcohol $\mathrm{OH}$ group $\left(\delta_{\text {alc }}(\mathrm{OH})\right)$ and the symmetric stretching of the carboxylate functionality $\left(\nu_{\text {sym }}(\mathrm{OCO})\right)$, respectively. This latter is in perfect agreement with what was found by Ashima et al. for acetic acid deposition on a $\mathrm{TiO}_{2}(110)$ surface [32]. The corresponding asymmetric vibration of the OCO group, which should appear at about $1600 \mathrm{~cm}^{-1}$, is not observed, possibly because the peak is covered by the intense residual contribution at $1500 \mathrm{~cm}^{-1}$ as proposed for acetic acid adsorption [32]. The peak observed at $1740 \mathrm{~cm}^{-1}$ for $5 \mathrm{~min}$ of dose is attributed to the $\nu(\mathrm{C}=\mathrm{O})$ mode of the carboxylic group and seems to shift to $1680 \mathrm{~cm}^{-1}$ at higher dosing times. The large downshift in frequency was already observed by infrared spectroscopy for TA adsorption on the $\mathrm{Cu}(110)$ [11] and $\mathrm{Ni}$ (110) [16] surfaces and ascribed to the formation of H-bonding interactions between the intact carboxylic acid groups of neighbouring molecules. The peak observed at about $2920-2930 \mathrm{~cm}^{-1}$ is assigned to $\mathrm{C}-\mathrm{H}$ vibration $(\nu(\mathrm{CH}))$. Moreover, information on the presence of surface hydroxyls species in the case of the dissociative adsorption behaviour of carboxylic acid groups could in principle be obtained by considering the corresponding hydroxyls vibrational modes in the HREELS spectra. In this respect, in a recent study the surface chemistry of methanol on $\mathrm{ZnO}$ single-crystal surfaces was elucidated by monitoring the formation of different $\mathrm{OH}$ groups by HREELS [52]. In the present work a weak loss is observed at about $3690 \mathrm{~cm}^{-1}$ both on the clean surface and after TA deposition, which can be attributed to the stretching 

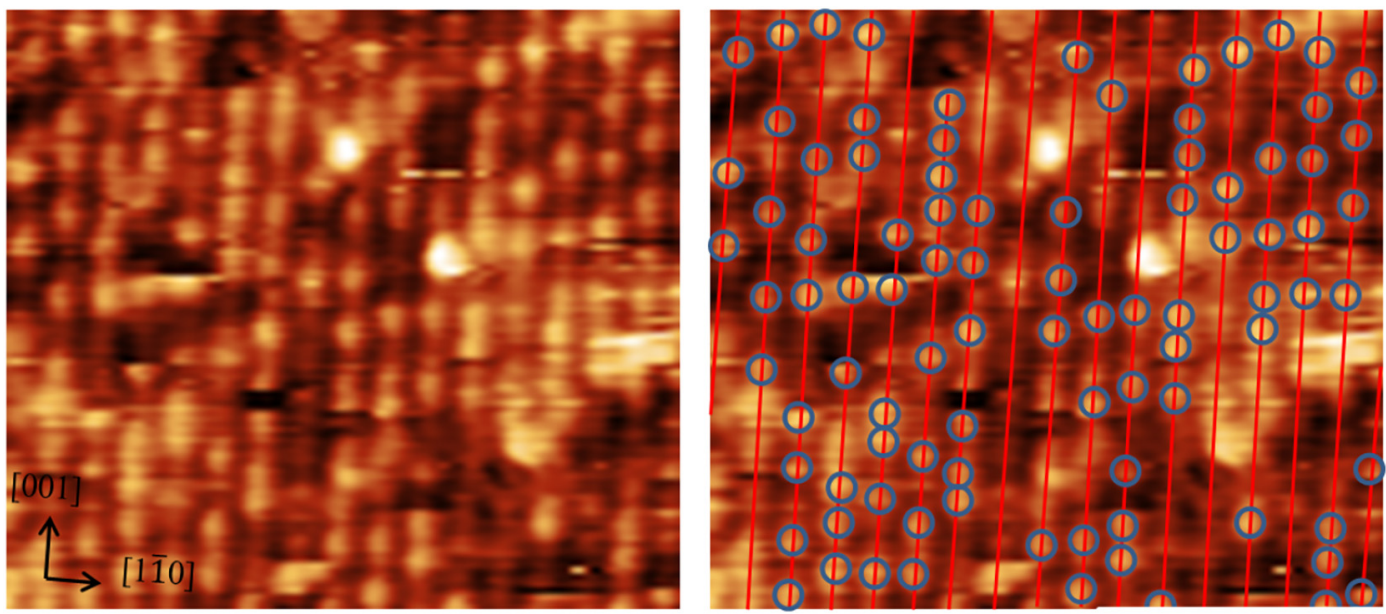

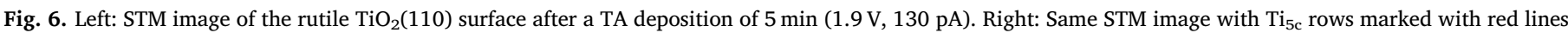
and TA molecules with blue circles.

vibrational mode $(\nu(\mathrm{OH}))$ of surface hydroxyls. However its weak intensity makes it barely distinguishable due to the weak transition dipole of the $\mathrm{O}-\mathrm{H}$ vibration, also reported in previous studies on carboxylic acids on $\mathrm{TiO}_{2}[22,32]$. For this reason, no reliable conclusions on $\nu(\mathrm{OH})$ intensity variations can be drawn in the present work. Finally, the observation of peaks associated both to the carboxylate functionality and to carboxylic acid groups are a signature of the presence of monotartrate species on the rutile (110) surface, in agreement with what was tentatively suggested from the XPS results.

Information on the $2 \mathrm{D}$ organisation and anchoring sites of RR-TA is provided by STM experiments. Fig. 6 shows a typical STM image for a RR-TA submonolayer deposition ( 5 min dosing). It has to be noted that, differently from the clean $\mathrm{TiO}_{2}$ surface in Fig. 1, where the bright $\mathrm{Ti}_{5 \mathrm{c}}$ and the dark $\mathrm{O}_{\mathrm{br}}$ rows are easily imaged, molecule imaging on oxide surfaces is a more challenging experiment since images are taken at room temperature, on non-metallic surfaces covered with organic adsorbates. The STM image has been calibrated using the $\mathrm{Ti}_{5 \mathrm{c}}$ interspacing distance set to $6.49 \AA$. At low coverages, molecules appear as disordered bright spots all over the surface and do not tend to organise into islands, in contrast to what is observed for TA on $\mathrm{Cu}(110)$ [11] or Ni(111) $[14,15]$. By marking with red lines the positions of the visible underlying $\mathrm{Ti}_{5 \mathrm{c}}$ rows and $\mathrm{TA}$ molecules with blue circles, we are able to identify the anchoring points of the molecules. More precisely, all molecules appear to be bound directly on top of $\mathrm{Ti}_{5 \mathrm{c}}$ rows, while no species in between two rows are detected.

By considering an image taken for a complete saturated monolayer (15 min dosing, Fig. 7(a)), where molecules are close to each other, the intermolecular distance can be estimated. The analysis performed shows that TA distances are on average $6.3 \pm 0.7 \AA$ in the [001] direction and $6.8 \pm 0.8 \AA$ in the [11̄0] direction, which correspond to about 2 and $1 \mathrm{TiO}_{2}$ surface unit cell parameters $(2.96 \AA \times 6.49 \AA)$, respectively. The deviation observed is due to the slight drift, which is not compensated for in this specific image. The intermolecular spacing measured thus corresponds to a $(2 \times 1)$ molecular adlayer. The occurrence of a $(2 \times 1)$ molecular adlayer is further confirmed by LEED. In this respect, Fig. 7(c) shows the LEED pattern after a TA dose of about 1 ML (saturated coverage). As evidenced in Fig. 7(c), in addition to the sharp $(1 \times 1)$ pattern attributed to the underlying $\mathrm{TiO}_{2}$ surface, a $(2 \times 1)$ pattern clearly appears upon molecular deposition, supporting the STM results.

Using the chemical and vibrational analysis obtained from XPS and HREELS and combining them with the structural information from STM and LEED, we are able to propose a model for TA adsorption on the rutile (110) surface (Fig. 7(b)). In this model, TA adsorption takes place in an upright position, with both carboxylate $\mathrm{O}$ atoms bound to two adjacent surface $\mathrm{Ti}_{5 \mathrm{c}}$ atoms and the intact carboxylic acid group extending out of the surface layer. The distance between adjacent $\mathrm{Ti}_{5 \mathrm{c}}$ atoms is consistent with the proposed model of bidentate bonding of the carboxylate group, as determined for formic acid deposition on the same rutile (110) surface by means of quantitative low energy electron diffraction [27] and photoelectron diffraction [26]. If each molecule is schematically represented by a black segment and placed on the $\mathrm{TiO}_{2}(110)$ surface as shown in Fig. 7(b), the observation of the $(2 \times 1)$ overlayer is easily explained. No molecular pairing due to interactions between neighbouring molecules is observed, in contrast to what was reported for Terephtalic Acid (TPA) molecules [36].

As mentioned in the introduction, adsorbed molecules sometimes assemble into 2D chiral structures, which develop along non-symmetric directions of the substrate surface. This is the case of RR-TA on $\mathrm{Cu}(110)$ and $\mathrm{Ni}(111)$, where both local point and global organisational chirality are observed, since molecules assemble into islands oriented along nonsymmetric direction of the substrate surface [7]. In this work STM images reveal a different behaviour for TA adsorption on $\mathrm{TiO}_{2}(110)$, with no formation of organized chiral arrays and thus a chiral expression limited to a local level as previously observed on $\mathrm{Ni}(110)$ [16] for instance.

\section{Conclusions}

Understanding the interaction between a chiral modifier and an oxide support is of central concern for the design of oxide-supported enantioselective metal catalysts. By using several surface science techniques, we investigated the $(R, R)$-tartaric acid chemical form and layer structure on rutile $\mathrm{TiO}_{2}(110)$, selected as model chiral modifier and oxide support, respectively. TA molecules are found to absorb in a monotartrate form, with both carboxylate $\mathrm{O}$ atoms bound to two adjacent $\mathrm{Ti}_{5 \mathrm{c}}$ atoms. The remaining carboxylic acid group is intact and protrudes above the surface layer. At saturation coverage, molecules are arranged in a $(2 \times 1)$ overlayer. The lack of extended chiral domains suggests that $\mathrm{TA}$ behaviour on $\mathrm{TiO}_{2}(110)$ substantially differs from what is observed on $\mathrm{Cu}(110)$ or $\mathrm{Ni}(111)$, revealing instead an adsorption geometry closer to that of TA on $\mathrm{Ni}(110)$. Chirality is thus not induced at a global level, but only locally due to the inherent TA chiral behaviour, which is at the same time at the heart of the most successful real enantioselective catalysts. More generally, the confirmation that TA adsorption takes place on the oxide surface already suggests that enantioselective induction is not limited to metallic surfaces but might also be driven by the oxide support. 
(a)

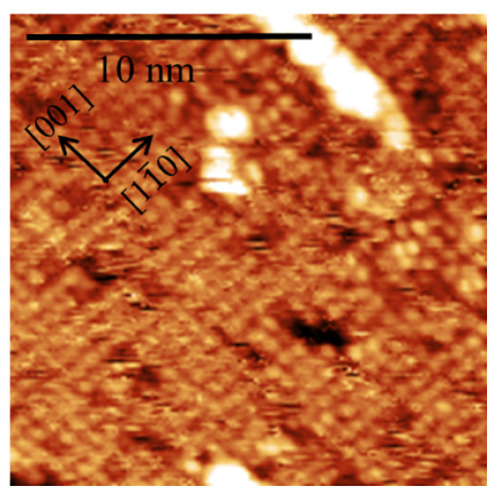

(c)

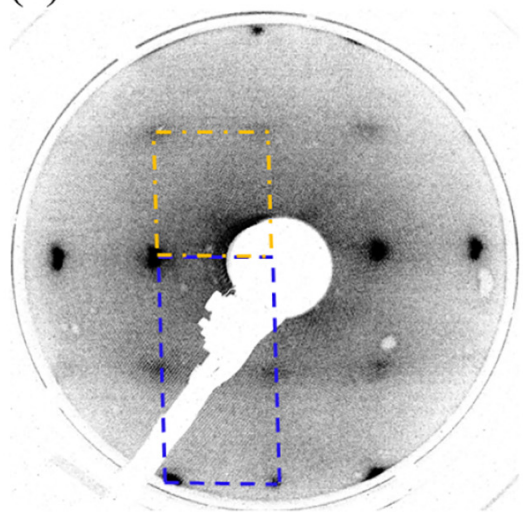

(b)
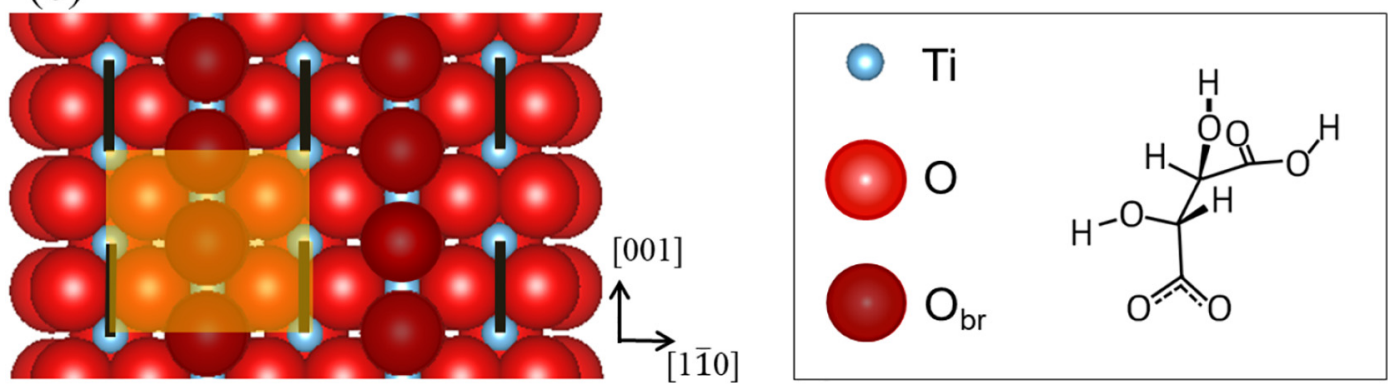

Fig. 7. (a) STM image of the rutile $\mathrm{TiO}_{2}(110)$ surface after a TA deposition of $15 \mathrm{~min}(1.7 \mathrm{~V}, 150 \mathrm{pA})$. (b) Schematic model proposed for TA adsorption on the rutile $\mathrm{TiO}_{2}(110)$ surface. Ti atoms, in plane $\mathrm{O}$ and bridging $\mathrm{O}$ atoms are depicted in blue, red and dark red, respectively. The monotartrate molecule is represented by a black segment corresponding to the carboxylate plane. The yellow rectangle displays the $(2 \times 1)$ overlayer formed by TA molecules. (c) LEED pattern observed after a TA deposition of $1 \mathrm{ML}$ on the rutile $\mathrm{TiO}_{2}(110)$. An electron beam energy of $45 \mathrm{eV}$ was used. The $(1 \times 1)$ and the $(2 \times 1)$ unit cells are indicated in blue and yellow, respectively.

\section{Acknowledgements}

This work was supported by the French state fund managed by the ANR within the Investissements d'Avenir programme under reference ANR-11-IDEX-0004-02, and more specifically within the framework of the Cluster of Excellence MATISSE.

\section{Appendix A. Supplementary data}

Supplementary data to this article can be found online at https:// doi.org/10.1016/j.apsusc.2019.07.143.

\section{References}

[1] K. Ding, Y. Uozumi, Handbook of Asymmetric Heterogeneous Catalysis, Wiley-VCH, Weinheim, 2008.

[2] M. Studer, H.-U. Blaser, C. Exner, Enantioselective hydrogenation using heterogeneous modified catalysts: an update, Adv. Synth. Catal. 345 (2003) 45-65, https://doi.org/10.1002/adsc.200390029.

[3] D.Y. Murzin, P. Mäki-Arvela, E. Toukoniitty, T. Salmi, Asymmetric heterogeneous catalysis: science and engineering, Catal. Rev. 47 (2005) 175-256, https://doi.org/ 10.1081/CR-200057461.

[4] T. Mallat, E. Orglmeister, A. Baiker, Asymmetric catalysis at chiral metal surfaces, Chem. Rev. 107 (2007) 4863-4890, https://doi.org/10.1021/cr0683663.

[5] K.-H. Ernst, Molecular chirality at surfaces, Phys. Status Solidi B 249 (2012) 2057-2088, https://doi.org/10.1002/pssb.201248188.

[6] R. Raval, Creating chiral architectures at metal surfaces, J. Phys. Condens. Matter 14 (2002) 4119-4132, https://doi.org/10.1088/0953-8984/14/16/305.

[7] S.M. Barlow, R. Raval, Complex organic molecules at metal surfaces: bonding, organisation and chirality, Surf. Sci. Rep. 50 (2003) 201-341, https://doi.org/10. 1016/S0167-5729(03)00015-3.

[8] C.J. Baddeley, N.V. Richardson, M. Bowker, P.R. Davies (Eds.), Scanning Tunneling Microscopy in Surface Science, Nanoscience and Catalysis, vol. 1, Wiley-VCH, Weinheim, 2010, pp. 1-27.

[9] A.J. Gellman, W.T. Tysoe, F. Zaera, Surface chemistry for enantioselective catalysis, Catal. Lett. 145 (2015) 220-232, https://doi.org/10.1007/s10562-014-1400-8.

[10] A. Baiker, Progress in asymmetric heterogeneous catalysis: design of novel chirally modified platinum metal catalysts, J. Mol. Catal. A Chem. 115 (1997) 473-493, https://doi.org/10.1016/S1381-1169(96)00352-4.

[11] M. Ortega Lorenzo, S. Haq, T. Bertrams, P. Murray, R. Raval, C.J. Baddeley, Creating chiral surfaces for enantioselective heterogeneous catalysis: RR-tartaric acid on Cu(110), J. Phys. Chem. B 103 (1999) 10661-10669, https://doi.org/10. 1021/jp992188i.

[12] M. Ortega Lorenzo, C.J. Baddeley, C. Muryn, R. Raval, Extended surface chirality from supramolecular assemblies of adsorbed chiral molecules, Nature 404 (2000) 376-379, https://doi.org/10.1038/35006031.

[13] M. Ortega Lorenzo, V. Humblot, P. Murray, C.J. Baddeley, S. Haq, R. Raval, Chemical transformations, molecular transport, and kinetic barriers in creating the chiral phase of $(R R)$-tartaric acid on $\mathrm{Cu}(110)$, J. Catal. 205 (2002) 123-134, https://doi.org/10.1006/jcat.2001.3422.

[14] T.E. Jones, C.J. Baddeley, A RAIRS, STM and TPD study of the Ni $\{111\} / R R$-tartaric acid system: modelling the chiral modification of Ni nanoparticles, Surf. Sci. 513 (2002) 453-467, https://doi.org/10.1016/S0039-6028(02)01812-5.

[15] T.E. Jones, C.J. Baddeley, An investigation of the adsorption of (RR)-tartaric acid on oxidised Ni \{111\} surfaces, J. Mol. Catal. A Chem. 216 (2004) 223-231, https:// doi.org/10.1016/j.molcata.2004.03.017.

[16] V. Humblot, S. Haq, C. Muryn, W.A. Hofer, R. Raval, From local adsorption stresses to chiral surfaces: (RR)-tartaric acid on Ni(110), J. Am. Chem. Soc. 124 (2002) 503-510, https://doi.org/10.1021/ja012021e.

[17] W.A. Hofer, V. Humblot, R. Raval, Conveying chirality onto the electronic structure of achiral metals: (RR)-tartaric acid on nickel, Surf. Sci. 554 (2004) 141-149, https://doi.org/10.1016/j.susc.2003.12.060.

[18] V. Humblot, S. Haq, C. Muryn, R. Raval, (RR)-tartaric acid on Ni(110): the dynamic nature of chiral adsorption motifs, J. Catal. 228 (2004) 130-140, https://doi.org/ 10.1016/j.jcat.2004.08.023.

[19] U. Diebold, The surface science of titanium dioxide, Surf. Sci. Rep. 48 (2003) 53-229, https://doi.org/10.1016/S0167-5729(02)00100-0.

[20] C.L. Pang, R. Lindsay, G. Thornton, Structure of clean and adsorbate-covered singlecrystal rutile $\mathrm{TiO}_{2}$ surfaces, Chem. Rev. 113 (2013) 3887-3948, https://doi.org/10 1021/cr300409r.

[21] H. Onishi, T. Aruga, Y. Iwasawa, Switchover of reaction paths in the catalytic decomposition of formic acid on $\mathrm{TiO}_{2}(110)$ surface, J. Catal. 146 (1994) 557-567, https://doi.org/10.1006/jcat.1994.1094.

[22] M.A. Henderson, Complexity in the decomposition of formic acid on the $\mathrm{TiO}_{2}(110)$ surface, J. Phys. Chem. B 101 (1997) 221-229, https://doi.org/10.1021/jp961494i.

[23] S.A. Chambers, M.A. Henderson, Y.J. Kim, S. Thevuthasan, Chemisorption geometry, vibrational spectra, and thermal desorption of formic acid on $\mathrm{TiO}_{2}(110)$, Surf. Rev. Lett. 5 (1998) 381-385, https://doi.org/10.1142/S0218625X98000700. 
[24] B.E. Hayden, A. King, M.A. Newton, Fourier transform reflection-absorption IR spectroscopy study of formate adsorption on $\mathrm{TiO}_{2}(110)$, J. Phys. Chem. B 103 (1999) 203-208, https://doi.org/10.1021/jp983581b.

[25] M. Bowker, P. Stone, R. Bennett, N. Perkins, Formic acid adsorption and decomposition on $\mathrm{TiO}_{2}(110)$ and on $\mathrm{Pd} / \mathrm{TiO}_{2}(110)$ model catalysts, Surf. Sci. 511 (2002) 435-448, https://doi.org/10.1016/S0039-6028(02)01540-6.

[26] D.I. Sayago, M. Polcik, R. Lindsay, R.L. Toomes, J.T. Hoeft, M. Kittel, D.P. Woodruff, Structure determination of formic acid reaction products on $\mathrm{TiO}_{2}(110)$, J. Phys. Chem. B 108 (2004) 14316-14323, https://doi.org/10.1021/jp049833s.

[27] R. Lindsay, S. Tomić, A. Wander, M. García-Médez, G. Thornton, Low energy electron diffraction study of $\mathrm{TiO}_{2}(110,2 \times 1)-[\mathrm{HCOO}]^{-}$, J. Phys. Chem. C 112 (2008) 14154-14157, https://doi.org/10.1021/jp804016d.

[28] D.C. Grinter, T. Woolcot, C.-L. Pang, G. Thornton, Ordered carboxylates on $\mathrm{TiO}_{2}(110)$ formed at aqueous interfaces, J. Phys. Chem. Lett. 5 (2014) 4265-4269, https://doi.org/10.1021/jz502249j.

[29] A. Mattsson, S. Hu, K. Hermansson, L. Österlund, Adsorption of formic acid on rutile $\mathrm{TiO}_{2}(110)$ revisited: an infrared reflection-absorption spectroscopy and density functional theory study, J. Chem. Phys. 140 (2014) 034705, , https://doi.org/10. 1063/1.4855176.

[30] I.D. Cocks, Q. Guo, R. Patel, E.M. Williams, E. Roman, J.L. de Segovia, The structure of $\mathrm{TiO}_{2}(110,1 \times 1,1 \times 2)$ surfaces with acetic acid adsorption - a PES study, Surf. Sci. 377-379 (1997) 135-139, https://doi.org/10.1016/S0039-6028(96) 01381-7.

[31] Q. Guo, E.M. Williams, The effect of adsorbate-adsorbate interaction on the structure of chemisorbed overlayers on $\mathrm{TiO}_{2}(110)$, Surf. Sci. 433-435 (1999) 322-326, https://doi.org/10.1016/S0039-6028(99)00105-3.

[32] H. Ashima, W.-J. Chun, K. Asakura, Room-temperature-adsorption behavior of acetic anhydride on a $\mathrm{TiO}_{2}$ (110) surface, Surf. Sci. 601 (2007) 1822-1830, https:// doi.org/10.1016/j.susc.2007.02.008.

[33] L. Patthey, H. Rensmo, P. Persson, K. Westermark, L. Vayssieres, A. Stashans, Å. Petersson, P.A. Brühwiler, H. Siegbahn, S. Lunell, N. Mårtensson, Adsorption of bi-isonicotinic acid on rutile $\mathrm{TiO}_{2}(110)$, J. Chem. Phys. 110 (1999) 5913-5918, https://doi.org/10.1063/1.478491.

[34] P. Persson, S. Lunell, P.A. Brühwiler, J. Schnadt, S. Södergren, J.N. O'Shea, O. Karis, H. Siegbahn, N. Mårtensson, M. Bässler, L. Patthey, N1s x-ray absorption study of the bonding interaction of bi-isonicotinic acid adsorbed on rutile $\mathrm{TiO}_{2}(110), \mathrm{J}$. Chem. Phys. 112 (2000) 3945-3948, https://doi.org/10.1063/1.480945.

[35] J. Schnadt, J. Schiessling, J.N. O'Shea, S.M. Gray, L. Patthey, M.K.-J. Johansson, M. Shi, J. Krempaský, J. Åhlund, P.G. Karlsson, P. Persson, N. Mårtensson, P.A. Brühwiler, Structural study of adsorption of isonicotinic acid and related

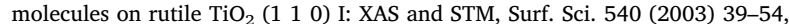
https://doi.org/10.1016/S0039-6028(03)00827-6.

[36] A. Tekiel, J.S. Prauzner-Bechcicki, S. Godlewski, J. Budzioch, M. Szymonski, Selfassembly of terephthalic acid on rutile $\mathrm{TiO}_{2}(110)$ : toward chemically functionalized metal oxide surfaces, J. Phys. Chem. C 112 (2008) 12606-12609, https://doi.org/ 10.1021/jp804979t.

[37] P. Rahe, M. Nimmrich, A. Nefedov, M. Naboka, C. Wöll, A. Kühnle, Transition of molecule orientation during adsorption of Terephthalic acid on rutile $\mathrm{TiO}_{2}(110), \mathrm{J}$. Phys. Chem. C 113 (2009) 17471-17478, https://doi.org/10.1021/jp9052117.
[38] W. Zhang, L. Cao, L. Wan, L. Liu, F. Xu, A photoelectron spectroscopy study on the interfacial chemistry and electronic structure of terephthalic acid adsorption on $\mathrm{TiO}_{2}(110-1 \times 1)$ surface, J. Phys. Chem. C 117 (2013) 21351-21358, https://doi. org/10.1021/jp406631x.

[39] K.L. Syres, A.G. Thomas, D.M. Graham, B.F. Spencer, W.R. Flavell, M.J. Jackman, V.R. Dhanak, Adsorption and stability of malonic acid on rutile $\mathrm{TiO}_{2}(110)$, studied by near edge X-ray absorption fine structure and photoelectron spectroscopy, Surf. Sci. 626 (2014) 14-20, https://doi.org/10.1016/j.susc.2014.03.015.

[40] M. Buchholz, M. Xu, H. Noei, P. Weidler, A. Nefedov, K. Fink, Y. Wang, C. Wöll, Interaction of carboxylic acids with rutile $\mathrm{TiO}_{2}(110)$ : IR-investigations of terephthalic and benzoic acid adsorbed on a single crystal substrate, Surf. Sci. 643 (2016) 117-123, https://doi.org/10.1016/j.susc.2015.08.006.

[41] E. Ataman, C. Isvoranu, J. Knudsen, K. Schulte, J.N. Andersen, J. Schnadt, Adsorption of $L$-cysteine on rutile $\mathrm{TiO}_{2}(110)$, Surf. Sci. 605 (2011) 179-186, https://doi.org/10.1016/j.susc.2010.10.017.

[42] S. Tanuma, C.J. Powell, D.R. Penn, Calculations of Electron inelastic mean free paths (IMFPs)VI. Analysis of the Gries inelastic scattering model and predictive IMFP equation, Surf. Interface Anal. 25 (1997) 25-35, https://doi.org/10.1002/ (SICI)1096-9918(199701)25:1 < 25::AID-SIA207>3.0.CO;2-2

[43] C. Yang, C. Wöll, IR spectroscopy applied to metal oxide surfaces: adsorbate vibrations and beyond, Adv. Phys. 2 (2017) 373-408, https://doi.org/10.1080/ 23746149.2017.1296372.

[44] Y. Wang, C. Wöll, IR spectroscopic investigations of chemical and photochemical reactions on metal oxides: bridging the materials gap, Chem. Soc. Rev. 46 (2017) 1875-1932, https://doi.org/10.1039/c6cs00914j.

[45] A. Rieger, C. Sax, T. Bauert, C. Wäckerlin, K.-H. Ernst, Chiral molecules adsorbed on a solid surface: tartaric acid diastereomers and their surface explosion on $\mathrm{Cu}(111)$, Chirality 30 (2018) 369-377, https://doi.org/10.1002/chir.22819.

[46] S. Baldanza, J. Ardini, A. Giglia, G. Held, Stereochemistry and thermal stability of tartaric acid on the intrinsically chiral $\mathrm{Cu}\{531\}$ surface, Surf. Sci. 643 (2016) 108-116, https://doi.org/10.1016/j.susc.2015.08.021.

[47] C. Roth, D. Passerone, L. Merz, M. Parschau, K.-H. Ernst, Two-dimensional selfassembly of chiral malic acid on cu(110), J. Phys. Chem. C 115 (2011) 1240-1247, https://doi.org/10.1021/jp106575g.

[48] M. Parschau, B. Behzadi, S. Romer, K.-H. Ernst, Stereoisomeric influence on 2D lattice structure: achiral meso-tartaric acid versus chiral tartaric acid, Surf. Interface Anal. 38 (2006) 1607-1610, https://doi.org/10.1002/sia.2426.

[49] V.E. Hendrich, P.A. Cox, The Surface Science of Metal Oxides, Cambridge University Press, Cambridge, 1994.

[50] R. Lazzari, J. Li, J. Jupille, Spectral restoration in high resolution electron energy loss spectroscopy based on iterative semi-blind Lucy-Richardson algorithm applied to rutile surfaces, Rev. Sci. Instrum. 86 (2015) 013906, , https://doi.org/10.1063/ 1.4905433

[51] P.A. Cox, W.R. Flavell, A.A. Williams, R.G. Egdell, Application of Fourier transform techniques to deconvolution of HREEL spectra, Surf. Sci. 152-153 (1985) 784-790, https://doi.org/10.1016/0039-6028(85)90488-1.

[52] L. Jin, Y. Wang, Surface chemistry of methanol on different ZnO surfaces studied by vibrational spectroscopy, Phys. Chem. Chem. Phys. 19 (2017) 12992-13001, https://doi.org/10.1039/C7CP01715D. 